\title{
Allometry and sexual dimorphism in the chela shape in the squat lobster Munida rugosa
}

\author{
Thomas Claverie $^{1,2, *}$, I. Philip Smith ${ }^{1}$ \\ ${ }^{1}$ University Marine Biological Station Millport, Isle of Cumbrae KA28 0EG, UK \\ ${ }^{2}$ Present address: Biology Department, 332 Morrill Science Center South, 611 North Pleasant Street, \\ University of Massachusetts Amherst, Amherst, Massachusetts 01003, USA
}

\begin{abstract}
Sexual selection generally promotes the development of ornaments or weapons that improve an individual's chance of mating. The squat lobster Munida rugosa exhibits a range of variation in chela (claw) morphology, with some individuals having a particular arched chela morphology, apparently specialized as a weapon. Geometric morphometric techniques were used to compare chela morphology across a wide size range and between sexes. The most fully developed arched morphology only occurred in large males, although not all large males possessed an arched claw, while smaller males retained straight, slender claws. Some large females exhibited a reduced version of the arched morphology. The pattern of occurrence of the arched morphology suggests that it is, or has been, subject to sexual selection through male-male competition for mates.
\end{abstract}

KEY WORDS: Munida rugosa - Secondary sexual dimorphism - Chela shape - Sexual selection · Weapon · Geometric morphometric

Resale or republication not permitted without written consent of the publisher

\section{INTRODUCTION}

Evolution of morphology in animals can be directed by natural selection (Darwin 1859) and sexual selection (Darwin 1871). In a given species, pressures directed by natural selection favour morphologies that facilitate individual survival, growth and reproduction, leading to an increase in fitness in a given environment (the 'struggle for life', Darwin 1859). Pressures associated with sexual selection directly promote traits that facilitate success in mating either through intrasexual competition or mate choice (Kodric-Brown \& Brown 1984). For example, across a wide range of taxa, weapons in males appear to have evolved through intrasexual selection (Emlen 2008). There are costs in developing such traits and only an increase in overall fitness can explain the evolution of a costly morphology (Bonduriansky \& Day 2003, Emlen 2008). In general, the magnitude of a sexually selected trait such as a weapon is related to the quality of the individual, in terms of competitive ability (i.e. honest signalling,
Emlen 2008). Growth of such structures is often positively allometric, with weapons or ornaments becoming disproportionately developed in larger or older individuals (Petrie 1988, 1992, Simmons \& Tomkins 1996, Knell \& Fortey 2005, Emlen 2008), but allometry is neither necessary nor sufficient evidence for a sexually selected trait (Bonduriansky 2007). Evolution of allometry in such traits requires individual condition to be related to body size and the selected trait to be under directional selective pressure (Bonduriansky 2007). Emlen (2008) also noted that the morphology of all exaggerated male weapons vary greatly among individuals within populations. Consequently, based on empirical evidence (Petrie 1988, 1992, Simmons \& Tomkins 1996, Knell \& Fortey 2005, Emlen 2008), a trait acting as a weapon has a good chance of being a sexually dimorphic structure that is positively allometric and variable in shape or size in mature males.

In decapod crustaceans, the first pereiopod generally bears a chela (claw) formed by a modification of the dactylus and propodus and is known as a cheliped. 
This appendage is typically used in feeding, defence against predators and agonistic behaviour, and has therefore been considered a multifunctional organ (Brown et al. 1979, Lee 1995). When this appendage is used as a weapon, it is to be expected that dominant individuals will have larger or stronger chelipeds and this has indeed been found in the few studies in which this has been investigated (Barki et al. 1997, Sneddon et al. 1997, 2000). Furthermore, allometric growth and sexual dimorphism in cheliped size is common in decapods, with males having larger chelipeds than females (Hartnoll 1974).

The squat lobster Munida rugosa has a peculiar chela morphology that can fulfil various functions, such as fighting and feeding (Claverie \& Smith 2007). There is sexual dimorphism in cheliped length (Claverie \& Smith 2009) but, in addition, some males develop a modified form (arched morphology, Fig. 1A) that is stronger and appears to be adapted to inflict puncture wounds on other males during intense agonistic interactions (Claverie \& Smith 2007). Moreover, field obser- vations indicate that large males chase other males away from their vicinity and they are often surrounded by females (T. Claverie pers. obs.). A closely related species, M. sarsi, has a similar claw morphology; claws are used in agonistic encounters involving cheliped grabbing (Berrill 1970) and male M. sarsi use chelipeds to restrain females during mating (Pothanikat 2005). Assuming that the arched chelae are better weapons than straight chelae (Claverie \& Smith 2007) and that agonistic interactions between males are primarily for access to females (intrasexual selection), we predict that arching is a sexually dimorphic feature with a high degree of variation in mature males. However, it is not clear to what extent the amplitude of arching is correlated to cheliped size, nor the relative contributions of these attributes to agonistic success.

Left-right asymmetry in chela shape (heterochely) is frequently observed in decapods (Crane 1975, Lee 1995, Mariappan et al. 2000) and is generally associated with adaptations for capture and handling of prey (Govind \& Pearce 1989, Lee 1995) but, as in the case
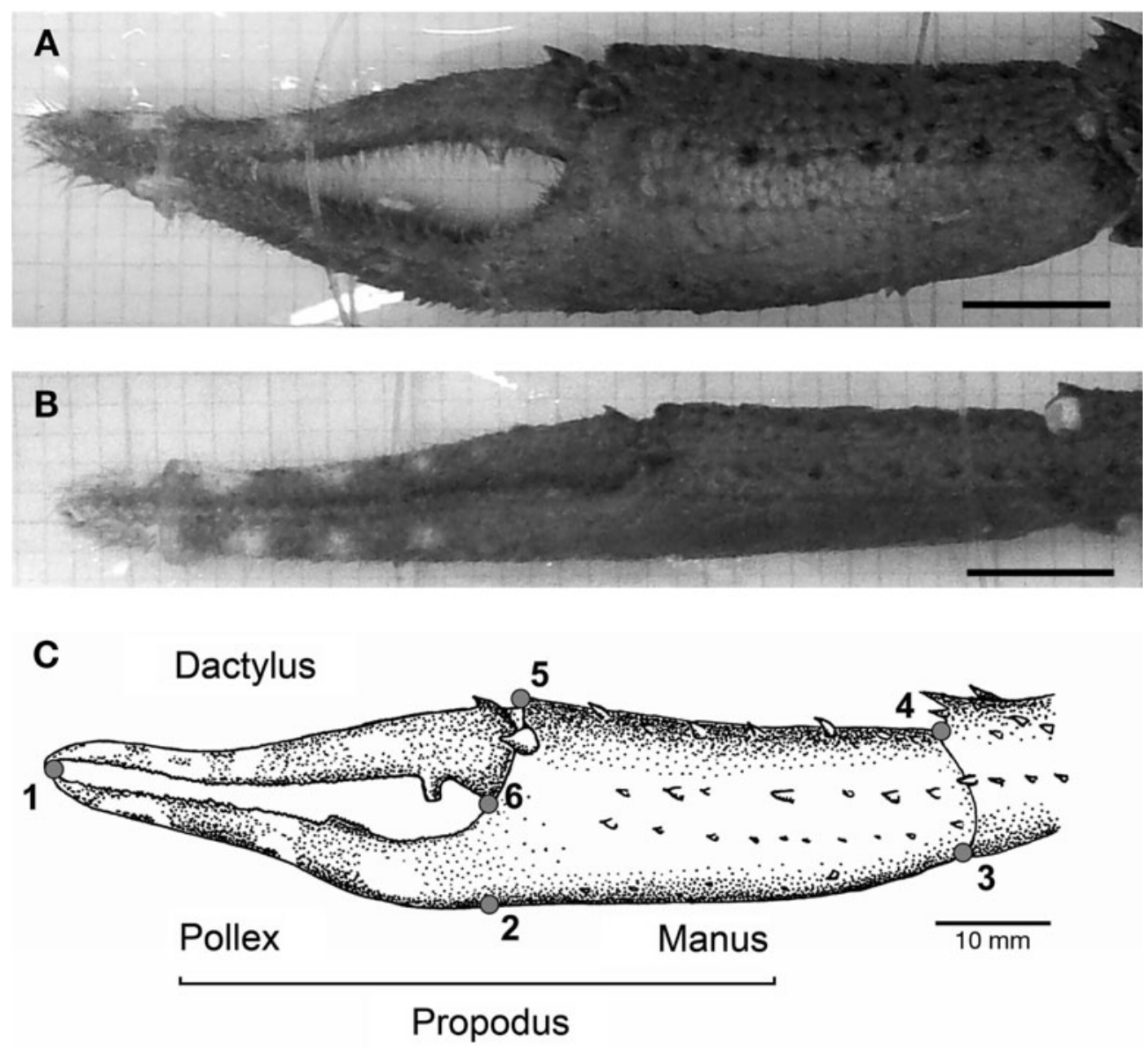

Fig. 1. Munida rugosa. Different chela morphologies encountered in Munida rugosa, (A) arched and (B) straight, and (C) associated landmarks ( 1 to 6 ) whose coordinates were recorded from each chela for analysis of shape. Drawing modified from Claverie \& Smith (2007) 
of fiddler crabs, can also be adapted for agonistic behaviour and female attraction (Crane 1975, Levinton et al. 1995). Heterochely is generally triggered at an early stage in development, either because of the loss of one cheliped or differential usage between left and right chelae (Govind \& Pearce 1989, Young et al. 1994, Goldstein \& Tlusty 2003). Moreover, in heterochelous species, homochelous specimens are rare (if they exist naturally at all) and occur generally only when animals are raised in artificial situations, such as in isolation (Govind \& Pearce 1989, Goldstein \& Tlusty 2003). Consequently, heterochely can be an important morphological feature in crustaceans arising from an underlying ontogenic mechanisms linked with the functional significance of particular chelae designs.

Claverie \& Smith (2007) argued that the arched morphology of Munida rugosa was better adapted to inflict injuries while retaining functionality for feeding (probably with the same effectiveness). Also, M. rugosa was observed to use both chelipeds during agonistic interactions (T. Claverie pers. obs.), as described for M. sarsi (Berrill 1970). Consequently, it is unlikely that selective pressures that normally act on decapod cheliped asymmetry (i.e. feeding ecology in durophagous crabs or agonistic interaction in fiddler crabs) would promote asymmetry in $M$. rugosa, since feeding and fighting could be performed with the arched design (Claverie \& Smith 2007). We therefore predict that there should be no consistent chela shape asymmetry in this species.

To investigate whether patterns in chela arching in Munida rugosa follow our predictions and are consistent with sexually selected traits, chela shape, symmetry and allometry were analysed in relation to body size, sex and cheliped size.

\section{MATERIALS AND METHODS}

Collection of specimens. Munida rugosa were collected in the Clyde Sea area, Scotland, by beamtrawling ( $2 \mathrm{~m}$ beam trawl, $50 \mathrm{~mm}$ mesh) on a gravelmud sea bed at water depths ranging from 35 to $40 \mathrm{~m}$ during spring 2005. Individuals with both chelipeds intact (no injury or mark of any previous moulting problem) were returned alive to the laboratory for examination. The carapace length $(\mathrm{CL}$, from the base of the rostral spine to the posterior margin of the carapace at the mid-line) of each individual was measured with vernier callipers to $0.1 \mathrm{~mm}$ accuracy. A total of 265 animals were measured (130 male and 84 female), ranging in CL from 13 to $38 \mathrm{~mm}$.

A digital photograph of the lateral surface of each cheliped was taken. Chelipeds were held extended and horizontal for the photograph using a custom- made jig. A small translucent elastic band was used to hold the chela closed. Photographs were taken with a digital camera (Fujifilm Finepix F810 in a WP-FX701 waterproof housing) in macro mode and mounted on the jig $25 \mathrm{~cm}$ vertically above the cheliped to standardize the picture and minimize distortion. The prodopus and dactylus are only slightly curved laterally, so analysis of chela shape in 2 dimensions was considered adequate. Cheliped length of each animal was measured from the photographs using the image analysis software SigmaScan Pro 5.0.0.

Variation in chela morphology. Geometric morphometric methods (Zelditch et al. 2004) were used to investigate variation in chela shape. Images of the right cheliped were reflected (in Adobe Photoshop Elements 2.0) to appear like the left cheliped to minimize digitising error (Rosenberg 2002) and to simplify symmetry analysis (Klingenberg \& McIntyre 1998, Klingenberg et al. 2002). 'Landmark' coordinates were recorded (pixel coordinates were subsequently scaled to distances in $\mathrm{mm}$ ) from the image with TpsDig2 (Rohlf 2005a). The 6 landmarks used were the same as those used previously (Claverie \& Smith 2007; Fig. 1C). They were: (1) the tip of the pollex; (2) the junction between the pollex and the manus on the inferior margin of the propodus; $(3,4)$ the lower and upper attachment points of the carpus with the propodus; and $(5,6)$ the upper and lower points marking the junction of the dactylus with the propodus.

A principal components analysis (PCA) was performed on the landmark coordinates, after procrustes superimposition using the TpsRelw program (Rohlf 2005b), to examine major trends of chela shape variation.

Relationship between chela shape and body size. Relationships between chela shape and CL, and between chela shape and cheliped length, were tested with multivariate regression. Separate analyses were performed for the left and right chelae for males and females. Significance was tested using the Wilks' lambda determinant ratio (Zelditch et al. 2004).

Variability of chela morphology in relation to CL was quantified for males and females. The first principal component (PC1) was plotted against CL. A running mean of PC1 was calculated on a $3 \mathrm{~mm}$ CL window across the full range of CL. Squared residual variation (standardised to $\mathrm{CL}$ ) of the $\mathrm{PC} 1$ value from the running mean was then calculated and the cumulative squared standardised residuals were plotted against CL. Residuals were divided by associated CL to represent a standardized measure of the shape variation (scaled to the size of animal) in order to correct for the amplitude of shape difference due to animal size. A deviation from a constant increase of cumulative standardised squared residual (greater or lesser rate of increase) would indicate variation in variability of chela shape 
for a given CL. PC1 was used to describe chela shape because it explained most of the variability (Claverie \& Smith 2007).

Chela shape difference between sexes and appendage side was tested using a 2-way permuted multivariate analysis of covariance (PERMANCOVA, 1000 permutations) on shape variables (partial procrustes distances) with sex and side as factors and cheliped length as the covariate. In order to exclude any bias from the analysis, only specimens of each sex within the same size range were included (cheliped length 54 to $114 \mathrm{~mm}$ ). The program Manovaboard 6.4 (Sheets 2006) was used for this analysis. This program uses a permutation test to determine significance (based on the sum of squared partial procrustes distances-shape variables - between and within groups) rather than a conventional MANCOVA procedure (i.e. using an F-test of a variance ratio).

Assessment of cheliped asymmetry. In addition to the PERMANCOVA described above, the correlations between chela shape difference (left versus right chelae) and cheliped length difference (left versus right cheliped), as well as the correlation between chela shape difference and CL, were tested with Spearman's rank correlation in order to assess whether chela shape asymmetry was related to body size or cheliped length asymmetry (i.e. regeneration of one of the chelipeds, Claverie \& Smith 2009). Shape differences were quantified using procrustes distance between left and right chelae (calculations were performed using the software Coordgen from the IMP series, Zelditch et al. 2004).

\section{RESULTS}

\section{Variation in chela morphology}

The first 3 principal components of the PCA together accounted for $94.7 \%$ of the shape variation $(76.48 \%$ for $\mathrm{PC} 1,13.78 \%$ for PC2 and $4.44 \%$ for PC3). Examination of the thin plate spline (TPS) representations of extreme forms on each axis indicates that the first axis mainly represents an inverse relationship between pollex (distal extension of the propodus) length and both manus (proximal part of the propodus) length and propodus height (Fig. 2a). Data points for females are mainly clustered on the negative part of the first axis, associated with narrower chelae, and only males reach high values on the first axis, associated with high propodus, long manus and short pollex. The second axis represents the degree of bending of the chela in the vertical plane, with an inflection point at the base of the pollex (Fig. 2a). The third axis represents variation in chela height (Fig. 2b).

\section{Relationship between chela shape and body size}

There was a significant relationship between chela shape and CL for both left (Wilks' $\lambda=0.35$, p $<0.001$ ) and right chelae (Wilks' $\lambda=0.39, \mathrm{p}<0.001$ ) in males;
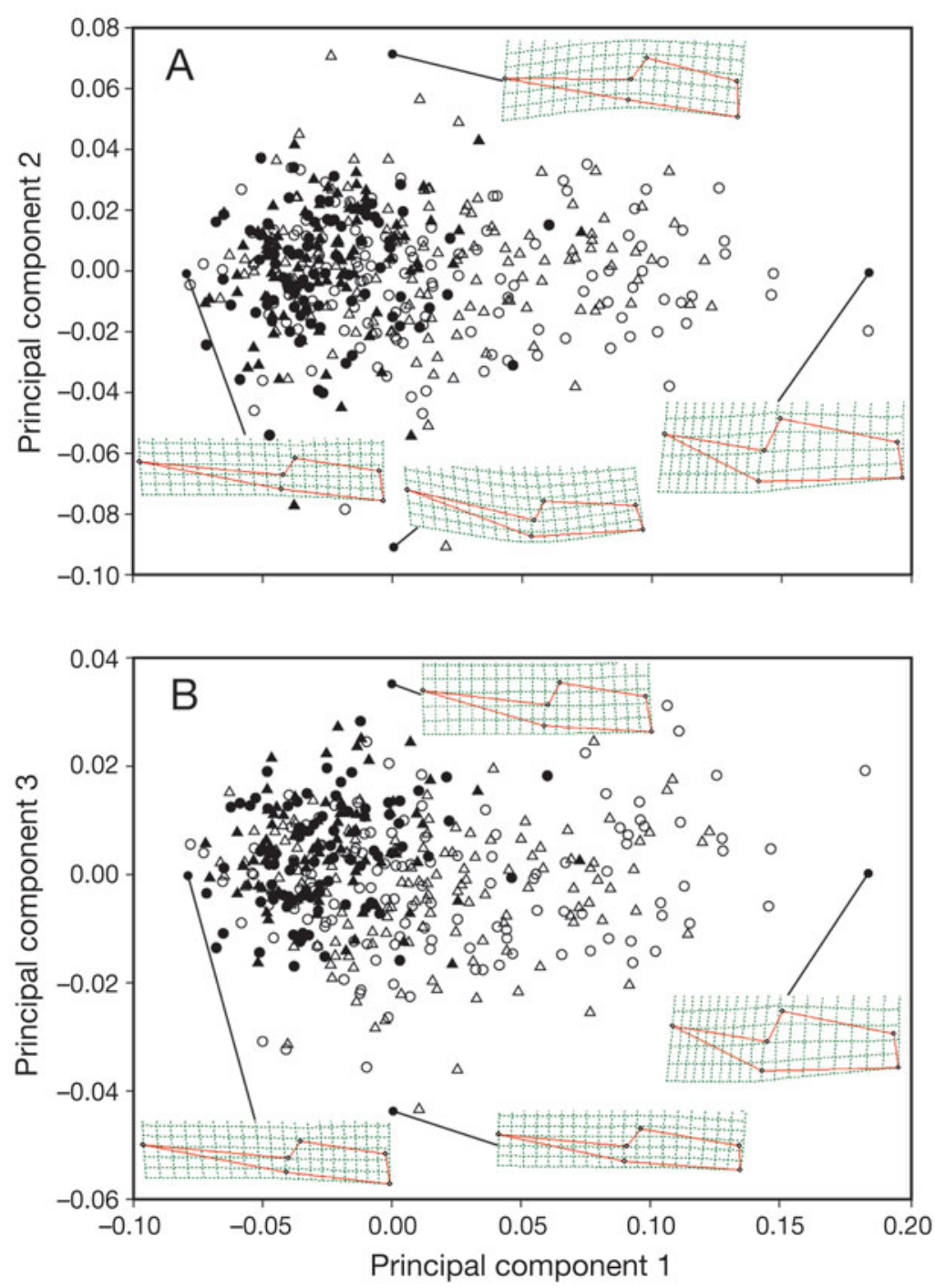

Fig. 2. Munida rugosa. Results of a principal components analysis, with thin plate spline representations of extreme landmark configurations on each axis. Relationships between (A) principal components 2 and 1, and (B) principal components 3 and 1. Filled symbols: females; open symbols: males; circle: left chela; triangle: right chela 
the linear model explained $35.39 \%$ of the variation of chelae shape for both sides. For females, similar relationships were found for the left (Wilks' $\lambda=0.58, \mathrm{p}<$ 0.001 ) and right chelae (Wilks' $\lambda=0.57, \mathrm{p}<0.001$ ), but the linear model explained only 14.71 and $13.45 \%$ of the variation in chela shape, respectively.

There was also a significant linear relationship between chela shape and cheliped length for both left (Wilks' $\lambda=0.27, \mathrm{p}<0.001$ ) and right chelae (Wilks' $\lambda=$ $0.30, \mathrm{p}<0.001$ ) in males, with the linear model explaining 40.24 and $40.41 \%$ of the shape variation, respectively (Fig. 3a). For females, the corresponding regressions were also significant (left: Wilks' $\lambda=0.60, \mathrm{p}<$ 0.001 ; right: Wilks' $\lambda=0.59, \mathrm{p}<0.001$; Fig. $3 \mathrm{~b}$ ), but again the linear model explained only 12.02 and $10.93 \%$ of the chela shape variation for left and right sides, respectively. In males, chela shape became higher with a relatively shorter pollex and a longer manus (i.e. more arched) with increasing cheliped length and CL, on average (Figs. 3a \& 4a). However, in females, chela shape changed little with increasing cheliped length and CL (Figs. 3b \& 4b).

A plot of the first axis of the PCA of chela shape (which accounted for most of the shape variation) against CL for males and females illustrates considerable variability in chela shape across the whole range of sizes (Fig. 4a,b). In males, there was a pronounced increase in chela shape variation at CL $>30 \mathrm{~mm}$ (Fig. 5a). Females, however, did not show such a distinct increase in chela shape variability with increasing CL (Fig. 5b).

Results from the PERMANCOVA showed that chela shape was significantly affected by cheliped size $(\mathrm{p}<$ 0.001) and differed between sexes ( $p<0.001)$, but there was no interaction between cheliped size and sex $(p=0.322)$, nor was there a difference between sides $(p=0.437)$. There was still no effect of side $(p=0.230)$ if all the specimens were included in the analysis (including the differing size ranges of males and females).

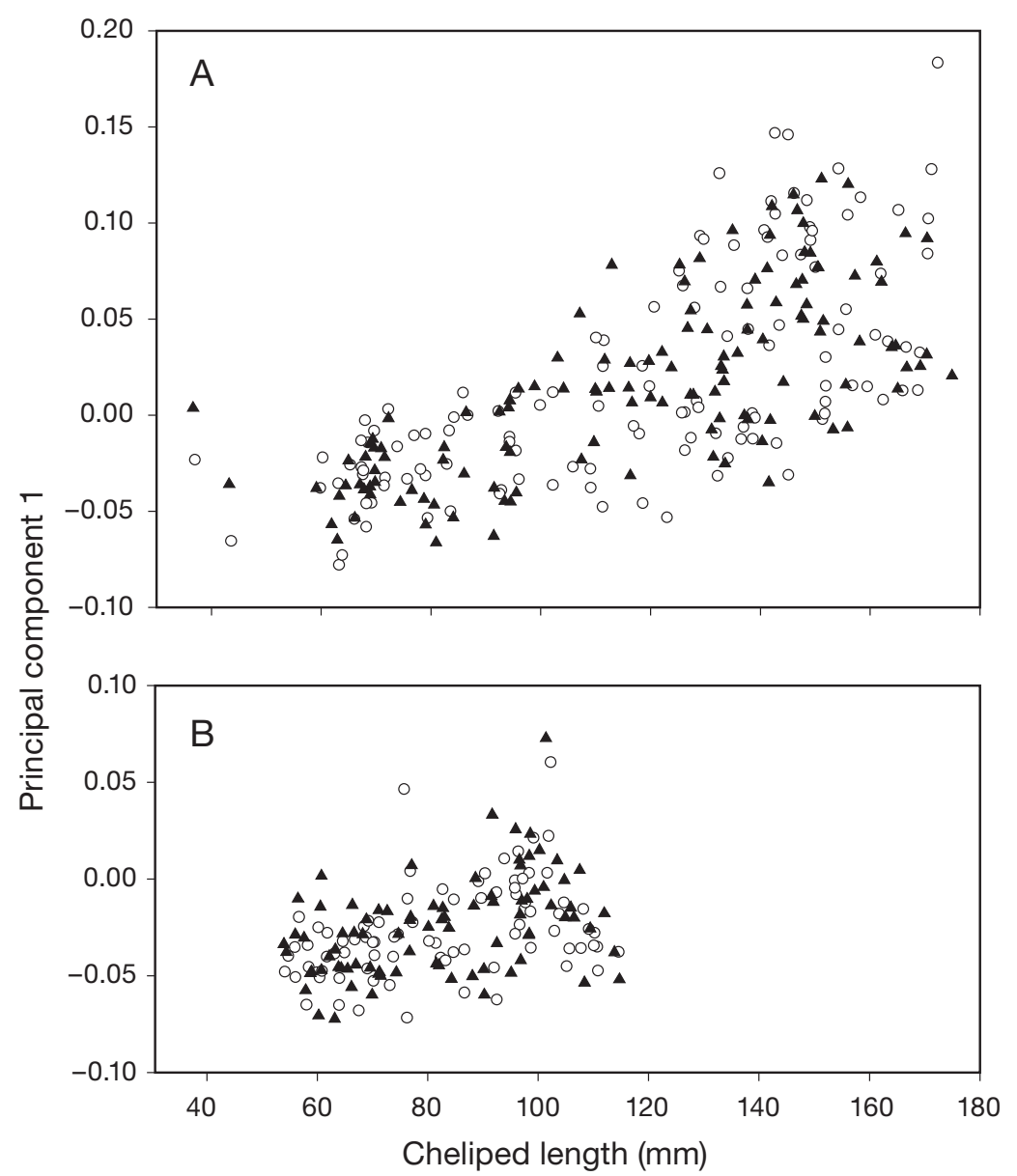

Fig. 3. Munida rugosa. The first axis of the principal component analysis of chela landmark configurations as a function of cheliped length for (A) males and (B) females. (O): left cheliped; ( $\mathbf{\Delta})$ : right cheliped

\section{Assessment of cheliped symmetry}

Difference in shape between left and right chelae (i.e. procrustes distance between the 2 chelae) was highly correlated with difference in cheliped length for males $\left(\mathrm{r}_{\mathrm{S}}=0.55, \mathrm{p}<0.001\right)$ and females $\left(\mathrm{r}_{\mathrm{S}}=\right.$ 0.32, $p=0.003$; Fig. 6a). However, the difference in chela shape between left and right was not correlated with $\mathrm{CL}$ for males $\left(\mathrm{r}_{\mathrm{S}}=0.15, \mathrm{p}=0.086\right)$ or females $\left(\mathrm{r}_{\mathrm{S}}=0.13, \mathrm{p}\right.$ $=0.226$; Fig. 6b).

\section{DISCUSSION}

Variation in chela morphology in Munida rugosa has been recorded in previous studies (Ingrand 1937, Zainal 1990, Hartnoll et al. 1992, Combes 2002, Claverie \& Smith 2007), but was not investigated further than a qualitative description in relation to body size. Claverie \& Smith (2007) noted variation from a straight morphology, with a narrow propodus and straight pollex and dactylus, to an arched morphology, with a higher propodus and bent pollex and dactylus leaving a gap in between. In the present study, a large variety of intermediate shapes was observed from narrow (straight) to broad (arched) propodi, with the greatest propodus heights observed only in males (represented by PC1). There was a positive relationship between the 


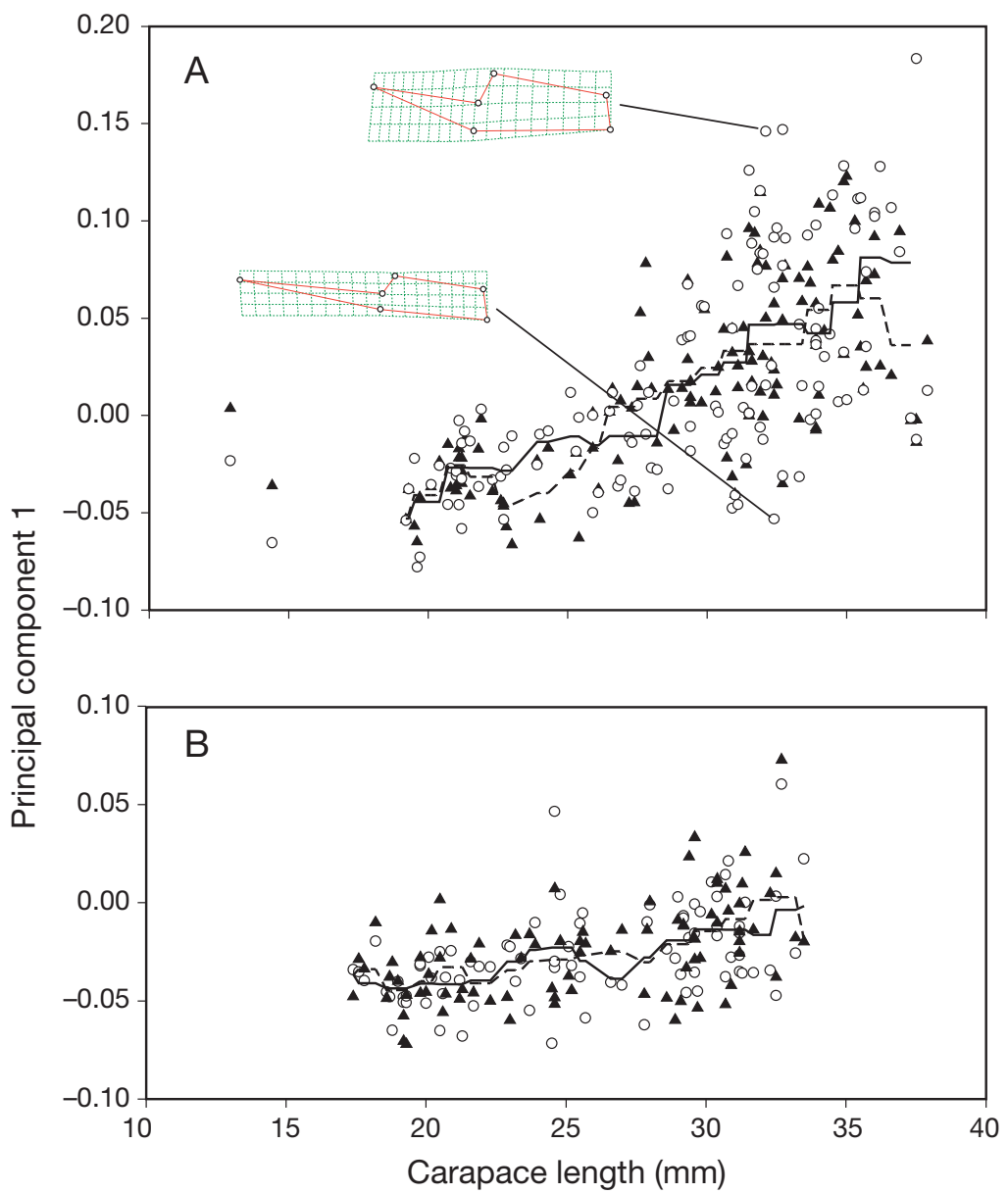

Fig. 4. Munida rugosa. The first axis of the principal component analysis as a function of carapace length with associated running means (window of $3 \mathrm{~mm}$ ) for (A) males (with thin plate spline representations of extreme landmark configurations) and (B) females. ( $O$, solid line): left cheliped; ( $\mathbf{\Delta}$, dashed line): right cheliped

amplitude of arching and CL and cheliped length, but with considerable variability. The amplitude of arching depended on cheliped size (the greatest arching was encountered in the longest chelipeds), but the reciprocal was not true, as the longest chelipeds were not always arched.

Chela shape varied from the straight towards the arched morphology in both sexes, but the fact that the degree of arching was greater in males (for equivalent female cheliped size and also because males developed longer chelipeds than females), suggests that there is stronger selection for this character in males. In both sexes, the arched morphology appeared only in individuals larger than the morphological size of maturity (Claverie \& Smith 2009). In males, however, variation in chela shape (due to development of the arched morphology) increased markedly above a CL of $30 \mathrm{~mm}$, whereas the size of morphological maturity indicated by cheliped length is $22 \mathrm{~mm}$ CL (Claverie \&
Smith 2009). It therefore appears that one secondary sexual feature (arched chelae) becomes prevalent 3 to 4 moults later than another (allometric cheliped growth, commonly encountered in decapods). This could be due to a slow development of arched morphology over several moults, perhaps because change in chela mass takes longer than an increase in cheliped length.

Claw morphology in Munida rugosa exhibits patterns previously observed for sexually selected traits (i.e. greater weapons in larger males, Petrie 1992, Simmons \& Tomkins 1996, Knell \& Fortey 2005, Emlen 2008), assuming that arched chelae are more effective weapons (Claverie \& Smith 2007). Alternative chela morphologies (i.e. straight) may represent alternative reproductive phenotypes within sexes associated with alternative tactics (phenotypic outcome) within a common strategy (decision rules, Dominey 1984). Such a strategy is commonly called a conditional strategy and is thought to be the most common evolutionary stable strategy in nature (Gross 1996). Using this strategy, males may adopt different tactics depending on their status in the population and fitness among tactics is not necessarily equal (Gross 1996). There is evidence for conditional strategies in some crustaceans. In Macrobrachium rosenbergii and Rhynchocinetes typus, for example, dominant or alpha males are more aggressive, have welldeveloped chelipeds and are superior in competition for access to food, shelter or mates. Subordinate males, on the other hand, retain relatively small chelipeds and use sneaking tactics to obtain these resources (Barki et al. 1992, Correa et al. 2003). When dominant males disappear, subordinate males replace them and become morphologically the new alpha males (Karplus 2005). In $M$. rugosa, one morphology (apparently the arched one since it is exaggerated only in large males) may be costly to develop, but could have greater benefits in terms of intrasexual competition or intersexual attraction and could be associated with dominant males (Claverie \& Smith 2007). The second morphology (in this case the straight one, since it appears more like a juvenile form) may be less costly to develop, but could confer limited disadvantages in intrasexual competition or intersexual attraction (e.g. not being able to hold firmly or injure conspecific) and would consequently be associated with subordinate males. Costs 


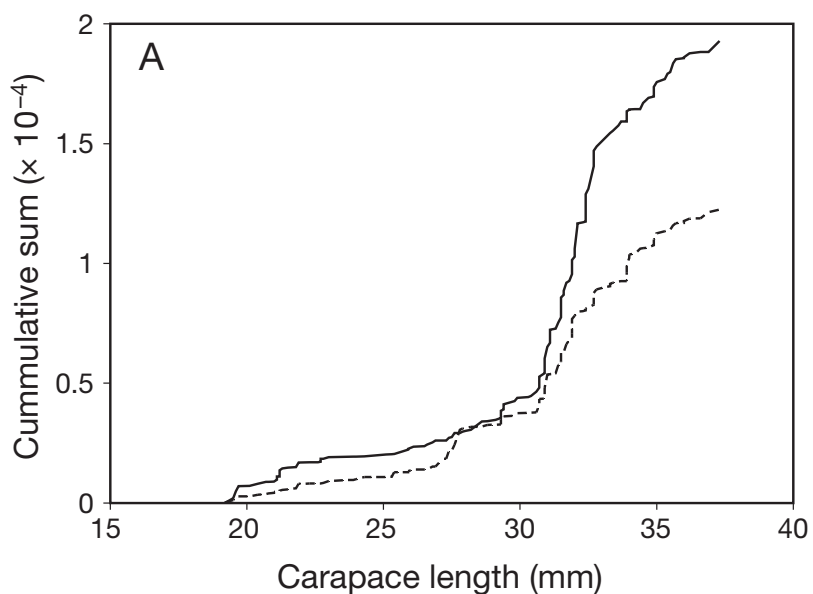

associated with the arched morphology could relate to the production of larger muscular and exoskeletal mass and greater energetic cost to maintain a bigger claw. The arched morphology could also impose a longer moulting time to extract the cheliped from exuvia, which may increase exposure to predators. Intermediate morphologies may represent a development towards the arched form. Under this hypothesis, both morphologies (representing different tactics) would likely be associated with behavioural adaptations appropriate to the difference in competitiveness (Dominey 1984).

Another possible explanation for the occurrence of straight chelae in large males is that autotomised chelipeds may take several moults to reacquire the arched morphology during regeneration, as suggested by Ingrand (1937) and Hartnoll et al. (1992). Intermediate morphologies would occur during regeneration. Studies in other decapods have shown that a particular cheliped morphology may take several moults to regenerate (Wilson 1903, Juanes \& Smith 1995, Read \& Govind 1997). In that case, the loss of an arched cheliped would have a high cost, since regeneration would be long (this species moult onces or twice a year depending on size) and fitness would consequently be adversely affected due to a reduction in competitive status.

Similar allometric slopes were found in the size-related change in chelae shape for males and females (i.e. non-significance of the interaction term between cheliped size and sex). Consequently, there may be a common genetic basis for chela arching in both sexes, with degree of arching being largely determined by the length of the cheliped (and maybe social status in the hypothesis of

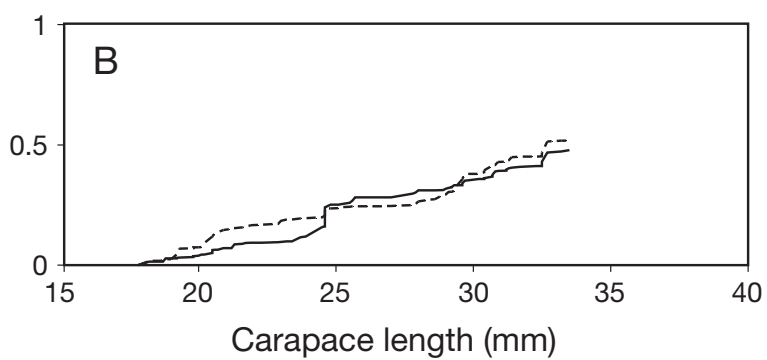

Fig. 5. Munida rugosa. Cumulative standardized squared residuals of the first axis of the principal component analysis scores from the running mean as a function of carapace length for (A) males and (B) females. Solid line: left cheliped; dashed line: right cheliped

a conditional strategy). Females have shorter chelipeds than males, on average (Claverie \& Smith 2009) and may, as a result, be less likely to develop the arched form exhibited by large males. However, the differences in shape between males and females were
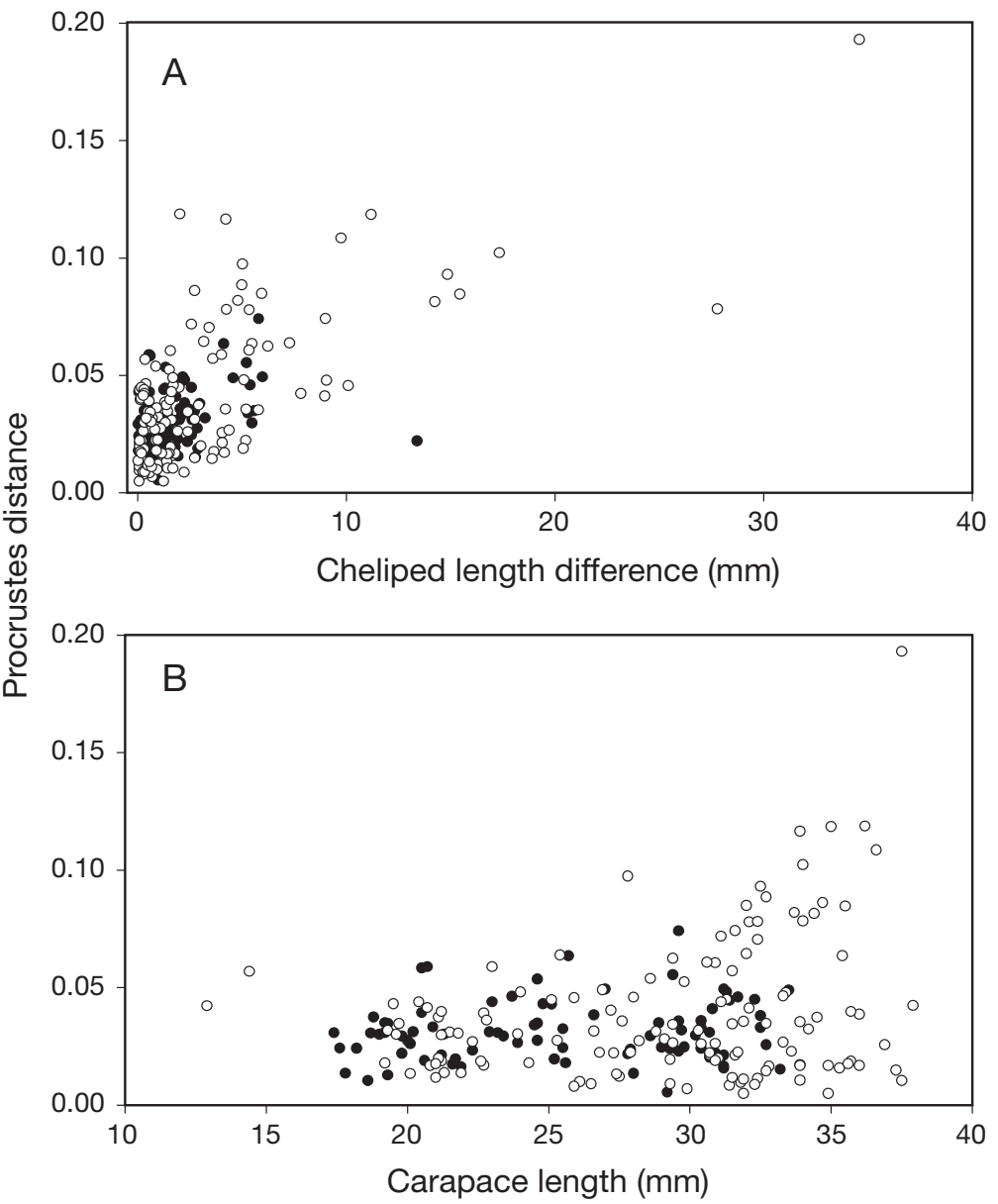

Fig. 6. Munida rugosa. Procrustes distance between left and right chelae as a function of (A) absolute cheliped length difference between left and right chelae and (B) carapace length. (०): males; (•) females 
not solely due to cheliped length, since females had less arched chelae than males of equivalent size. Nevertheless, there may be intrasexual competition among females, giving rise to a certain level of selection for this trait (Kodric-Brown \& Brown 1984). If so, the limited degree of arching in females implies lower selection pressure for arched chelae and correspondingly lower intensity of competition mediated through agonistic interactions using the chelipeds than in males.

No significant asymmetry was measured in chela shape of Munida rugosa and most specimens were approximately symmetrical in cheliped length (Claverie \& Smith 2009). In the present study, some specimens were heterochelous but no specific handedness was observed, and shape asymmetry was correlated with the asymmetry in cheliped length (with the longer claw being the most arched). Some asymmetry in arching was previously reported for this species (Zainal 1990, Hartnoll et al. 1992, Combes 2002), but findings were not consistent. $M$. rugosa possess long and slender chelipeds and autotomise these appendages more readily when handled (particularly ovigerious females, T. Claverie pers. obs.) than crabs or lobsters with more robust chelipeds. Hartnoll et al. (1992) suggested that arching could take several moults to develop. The high prevalence of symmetric specimens in the population sampled, combined with the correlation between shape and length difference, strongly suggests that the observed asymmetries in cheliped length and chela shape could be the result of regeneration after autotomy.

In summary, Munida rugosa exibit a sexual dimorphism where males are larger than females, possess longer chelipeds and can have a greater degree of chela arching. However, considerable variation in the degree of arching was observed for large males and only some of the largest individuals fully developed arched chelae. Considering the various examples of exaggerated traits occurring in the animal kingdom related to sexual selection (Zahavi 1975, Siva-Jothy 1987, Emlen \& Nijhout 2000, Hongo 2003, Emlen 2008 ) and similar patterns observed in other decapods associated with male-male interactions (Crane 1975, Barki et al. 1992), it seems possible that sexual selection has favoured the evolution of longer chelipeds with a greater degree of chela arching (weapons) in mature male M. rugosa. However, the effect of arching on the outcome of intrasexual conflict remains to be quantified. It is to be expected that males with arched chelae would be more successful in agonistic interactions or in obtaining and handling mates than similar-sized males with straight chelae. These predictions are readily testable with behavioural experiments.
Acknowledgements. This study was funded by the Sheina Marshall Bequest. We acknowledge C. Klingerberg, M. Zelditch and D. Swiderski for helpful discussions on geometric morphometric analysis. We also thank the anonymous reviewers of this manuscript for their valuable comments. Thank you to the crew of the R/V 'Aplysia' and the divers of the University Marine Biological Station Millport for their help with sampling and measurements.

\section{LITERATURE CITED}

Barki A, Karplus I, Goren M (1992) Effects of size and morphotype on dominance hierarchies and resource competition in the freshwater prawn Macrobrachium rosenbergii. Anim Behav 44:547-555

Barki A, Harpaz S, Karplus I (1997) Contradictory asymmetries in body and weapon size, and assessment in fighting male prawns, Macrobrachium rosenbergii. Aggress Behav 23:81-91

Berrill M (1970) The aggressive behavior of Munida sarsi (Crustacea: Galatheidae). Sarsia 43:1-11

Bonduriansky R (2007) Sexual selection and allometry: a critical reappraisal of the evidence and ideas. Evolution 61: 838-849

Bonduriansky R, Day T (2003) The evolution of static allometry in sexually selected traits. Evolution 57:2450-2458

Brown SC, Cassuto SR, Loos RW (1979) Biomechanics of chelipeds in some decapod crustaceans. J Zool 188: 143-159

Claverie T, Smith IP (2007) Functional significance of an unusual chela dimorphism in a marine decapod: specialization as a weapon? Proc R Soc Lond B 274:3033-3038

Claverie T, Smith IP (2009) Morphological maturity and allometric growth in the squat lobster Munida rugosa. J Mar Biol Assoc UK 89:1189-1194

Combes JCH (2002) Aspects of the biology and fisheries ecology of the velvet swimming crab, Necora puber (L.), and the squat lobsters Munida rugosa (Fabricius) and M. sarsi Huus (Crustacea: Decapoda) in Scottish waters. PhD thesis, University of London

Correa C, Baeza JA, Hinojosa IA, Thiel M (2003) Male dominance hierarchy and mating tactics in the rock shrimp Rhynchocinetes typus (Decapoda: Caridea). J Crustac Biol 23:33-45

Crane J (1975) Fiddler crabs of the world (Ocypodidae: genus Uca). Princeton University Press, Princeton, NJ

Darwin C (1859) On the origin of species by means of natural selection, or the preservation of favoured races in the struggle for life. John Murray, London

Darwin C (1871) The descent of man, and selection in relation to sex. Princeton University Press, Princeton, NJ

Dominey WJ (1984) Alternative mating tactics and evolutionarily stable strategies. Am Zool 24:385-396

Emlen DJ (2008) The evolution of animal weapons. Annu Rev Ecol Evol Syst 39:387-413

Emlen DJ, Nijhout HF (2000) The development and evolution of exaggerated morphologies in insects. Annu Rev Entomol 45:661-708

Goldstein JS, Tlusty MF (2003) Substrate determinants and developmental rate of claw asymmetry in American lobsters, Homarus americanus. J Crustac Biol 23:890-896

Govind CK, Pearce J (1989) Critical period for determining claw asymmetry in developing lobsters. J Exp Zool 249: 31-35

> Gross MR (1996) Alternative reproductive strategies and tactics: diversity within sexes. Trends Ecol Evol 11:92-98 
Hartnoll RG (1974) Variation in growth pattern between some secondary sexual characters in crabs (Decapoda Brachyura). Crustaceana 27:131-136

Hartnoll RG, Rice AL, Attrill MJ (1992) Aspects of the biology of the galatheid genus Munida (Crustacea, Decapoda) from the Porcupine Seabight, Northeast Atlantic. Sarsia 76:231-246

Hongo Y (2003) Appraising behaviour during male-male interaction in the Japanese horned beetle Trypoxylus dichotomus septentrionalis (Kono). Behaviour 140:501-517

Ingrand M (1937) Morphologie des pinces et caractères sexuels secondaires de Munida bamffica. Trav St Biol Roscoff 15:57-86

- Juanes F, Smith LD (1995) The ecological consequences of limb damage and loss in decapod crustaceans: a review and prospectus. J Exp Mar Biol Ecol 193:197-223

Karplus I (2005) Social control of growth in Macrobrachium rosenbergii (De Man): a review and prospects for future research. Aquac Res 36:238-254

Klingenberg CP, McIntyre GS (1998) Geometric morphometrics of developmental instability: analysing patterns of fluctuating asymmetry with procrustes methods. Evolution 52:1363-1375

Klingenberg CP, Barluenga M, Meyer A (2002) Shape analysis of symmetric structures: quantifying variation among individuals and asymmetry. Evolution 56:1909-1920

Knell RJ, Fortey RA (2005) Trilobite spines and beetle horns: sexual selection in the Paleozoic? Biol Lett 1:196-199

Kodric-Brown A, Brown JH (1984) Truth in advertising: the kinds of traits favored by sexual selection. Am Nat 124: 309-323

Lee SY (1995) Cheliped size and structure: the evolution of a multifunctional decapod organ. J Exp Mar Biol Ecol 193: 161-176

Levinton JS, Judge ML, Kurdziel JP (1995) Functional differences between the major and the minor claws of fiddler crabs (Uca, family Ocypodidae, order Decapoda, subphylum Crustacea): a result of selection or developmental constraint? J Exp Mar Biol Ecol 193:147-160

Mariappan P, Balasundaram C, Schmitz B (2000) Decapod crustacean chelipeds: an overview. J Biosci 25:301-313

Petrie M (1988) Intraspecific variation in structures that display competitive ability: large animals invest relatively more. Anim Behav 36:1174-1179

Petrie M (1992) Are all secondary sexual display structures

Editorial responsibility: Victor Meyer-Rochow,

Bremen, Germany positively allometric and, if so, why? Anim Behav 43: 173-175

Pothanikat RME (2005) The behaviour and ecology of Munida rugosa and Munida sarsi. PhD thesis, Queen's University Belfast

Read AT, Govind CK (1997) Regeneration and sex-biased transformation of the sexually dimorphic pincer claw in adult snapping shrimps. J Exp Zool 279:356-366

Rohlf FJ (2005a) TpsDig, digitize landmarks and outlines, v. 2.05. Department of Ecology and Evolution, State University of New York at Stony Brook, Stony Brook, NY

Rohlf FJ (2005b) TpsRelw, relative warps, v. 2.05. Department of Ecology and Evolution, State University of New York at Stony Brook, Stony Brook, NY

Rosenberg MS (2002) Fiddler crab claw shape variation: a geometric morphometric analysis across the genus UCa (Crustacea: Brachyura: Ocypodidae). Biol J Linn Soc 75:147-162

Sheets HD (2006) IMP: Manovaboard 6.4. Department of Physics, Canisius College, Buffalo, NY

Simmons LW, Tomkins JL (1996) Sexual selection and the allometry of earwig forceps. Evol Ecol 10:97-104

Siva-Jothy MT (1987) Mate securing tactics and the cost of fighting in the Japanese horned beetle, Allomyrina dichotoma L. (Scarabaeidae). J Ethol 5:165-172

Sneddon LU, Huntingford FA, Taylor AC (1997) Weapon size versus body size as a predictor of winning in fights between shore crabs, Carcinus maenas (L.). Behav Ecol Sociobiol 41:237-242

Sneddon LU, Huntingford FA, Taylor AC, Orr JF (2000) Weapon strength and competitive success in the fights of shore crabs (Carcinus maenas). J Zool 250:397-403

Wilson EB (1903) Notes on the reversal of asymmetry in the regeneration of the chelae in Alpheus heterochelis. Biol Bull 4:197-210

Young RE, Pearce J, Govind CK (1994) Establishment and maintenance of claw bilateral asymmetry in snapping shrimps. J Exp Zool 269:319-326

Zahavi A (1975) Mate selection - a selection for a handicap. J Theor Biol 53:205-214

Zainal KAY (1990) Aspects of the biology of the squat lobster, Munida rugosa (Fabricius, 1775). PhD thesis, University of Glasgow

Zelditch ML, Swiderski DL, Sheets HD, Fink WL (2004) Geometric morphometrics for biologists: a primer. Elsevier Academic Press, New York

Submitted: April 24, 2009; Accepted: February 10, 2010 Proofs received from author(s): February 27, 2010 